\title{
The effect of ultrasound on casein micelle integrity
}

\author{
J. Chandrapala, ${ }^{*}$ G. J. O. Martin, ${ }^{* 1}$ B. Zisu,† S. E. Kentish, ${ }^{*}$ and M. Ashokkumar ${ }^{*}$ \\ ${ }^{*}$ School of Chemistry/Department of Chemical and Biomolecular Engineering, University of Melbourne, Victoria 3010, Australia \\ †Dairy Innovation Australia, Synedes Road, Werribee, Victoria 3030, Australia
}

\begin{abstract}
Samples of fresh skim milk, reconstituted micellar casein, and casein powder were sonicated at $20 \mathrm{kHz}$ to investigate the effect of ultrasonication. For fresh skim milk, the average size of the remaining fat globules was reduced by approximately $10 \mathrm{~nm}$ after $60 \mathrm{~min}$ of sonication; however, the size of the casein micelles was determined to be unchanged. A small increase in soluble whey protein and a corresponding decrease in viscosity also occurred within the first few minutes of sonication, which could be attributed to the breakup of casein-whey protein aggregates. No measurable changes in free casein content could be detected in ultracentrifuged skim milk samples sonicated for up to $60 \mathrm{~min}$. A small, temporary decrease in $\mathrm{pH}$ resulted from sonication; however, no measurable change in soluble calcium concentration was observed. Therefore, casein micelles in fresh skim milk were stable during the exposure to ultrasonication. Similar results were obtained for reconstituted micellar casein, whereas larger viscosity changes were observed as whey protein content was increased. Controlled application of ultrasound can be usefully applied to reverse process-induced protein aggregation without affecting the native state of casein micelles.
\end{abstract}

Key words: ultrasonication, casein micelle, dynamic light scattering, viscosity

\section{INTRODUCTION}

Considerable interest has been expressed in using ultrasound for improving the functional properties of dairy products (Ashokkumar et al., 2008). Ultrasound has been shown to be a potential alternative to thermal treatment for reducing microbial activity (Piyasena et al., 2003), an effective method for homogenizing milk fat (Villamiel and de Jong, 2000), and a means of improving the heat stability of whey protein concentrates (WPC) (Ashokkumar et al., 2009a,b). Ultrasonication

Received January 3, 2012.

Accepted September 8, 2012.

${ }^{1}$ Corresponding author: gjmartin@unimelb.edu.au can impart changes to aqueous systems such as milk by acoustic cavitation and a range of accompanying physical and chemical effects. When subjected to an acoustic field, bubbles grow in size because of both rectified diffusion and coalescence. The bubbles eventually collapse, generating extreme temperatures within the bubbles, which leads to the generation of radicals (Ashokkumar et al., 2007). Shock waves are also formed, causing localized turbulence with extreme shear forces.

Although the general mechanistic actions of ultrasound have been well studied, much is still to be learned about the effect of these actions on milk and its various components. Milk is a complex biochemical system. It is an aqueous lactose solution containing a complex mixture of mineral salts, an oil-in-water emulsion of fat globules, a variety of soluble whey proteins, and colloidal protein associations called $\mathrm{CN}$ micelles. Some knowledge exists regarding the effect of ultrasound on the fat and whey protein components of milk. It has been shown that ultrasound can reduce the size of milk fat globules (Villamiel and de Jong, 2000; Wu et al., 2001). This effect can be attributed to the localized shear forces induced by ultrasonication. The application of ultrasound has been shown to break apart heat-induced protein aggregates in WPC and prevent their reformation on subsequent heating (Ashokkumar et al., 2009a,b). The breakdown of the heat-induced aggregates is attributed primarily to the physical shear forces resulting from acoustic cavitation, although minor whey protein structural changes are observed (Chandrapala et al., 2011). Ultrasound has also been shown to improve the gelation properties of WPC systems (Zisu et al., 2011).

Of the work to date on $\mathrm{CN}$-containing systems, considerable focus has been given to understanding the effects of ultrasound on bulk physical and functional properties. Our own work has shown that sonication of both CN-rich milk protein concentrate retentate and calcium caseinate can significantly reduce solution viscosity (Zisu et al., 2010). These effects were attributed to the disruption of $\mathrm{CN}-\mathrm{CN}$ or $\mathrm{CN}$-whey protein interactions, or both, but no evidence was presented to support this hypothesis. The effect of ultrasonication on milk gels has also been reported (Vercet et al., 2002; 
Riener et al., 2009, 2010; Nguyen and Anema, 2010; Zisu et al., 2011). Acid gel firmness $\left(\mathrm{G}^{\prime}\right)$ was found to be altered when skim milk was ultrasonically treated before acidification, although the effect was attributed largely to denaturation of whey protein caused simply by temperature increases (up to about $95^{\circ} \mathrm{C}$ ) resulting from sonication performed without temperature control (Nguyen and Anema, 2010). The simultaneous application of heat and ultrasound under moderate pressure (manothermosonication) has enabled the formation of improved yogurt gels of greater strength compared with those obtained from untreated milk (Vercet et al., 2002). The cause of this behavior was not ascertained. Although the authors suggested that a difference in the size of fat globules was not responsible, a proper comparison of the fat globules was not performed. Other researchers also found that thermosonication improved the rheological properties of yogurts (Riener et al., 2009, 2010) and presented data showing a significant decrease in the size of fat globules in the sonicated milk.

Although CN micelles are considered relatively stable particles, their composition and size respond to alterations in $\mathrm{pH}$, temperature, and milk protein concentration (Martin et al., 2007; Tsioulpas et al., 2007; Dalgleish, 2011). It is possible that the localized high temperatures and shear forces created by ultrasonication could physically alter the $\mathrm{CN}$ micelles or their interactions with other milk components. One study found that the average size of reassembled $\mathrm{CN}$ micelles could be reduced by exposure to ultrasound $(35 \mathrm{kHz}$ frequency) for $6 \mathrm{~h}$, provided the $\mathrm{pH}$ was above 8 (Madadlou et al., 2009). However, it is unclear how this relates to native $\mathrm{CN}$ micelles because the reassembled CN particles were considerably larger $(275 \mathrm{~nm})$ and structurally and functionally different (Mounsey et al., 2005). In another study involving true CN micelles, a decrease in particle size resulting from ultrasonication was observed. This particle size decrease was attributed to a reduction in $\mathrm{CN}$ micelle size; however, this was not substantiated (Nguyen and Anema, 2010).

To date, no systematic study on the effect of ultrasonication on $\mathrm{CN}$ micelles has been performed. It is unknown what, if any, effect ultrasound has on the structure, size, or composition of CN micelles, or their interactions with whey proteins. The purpose of this study was to investigate possible alterations to the size of CN micelles resulting from the application of high-intensity ultrasound. To investigate the effect of ultrasound on native $\mathrm{CN}$ micelles, experiments were performed on fresh, pasteurized skim milk, including particle size and soluble CN analysis. To isolate the effects of ultrasound on fat globules from those on $\mathrm{CN}$ micelles, particle size analysis was performed on skim milk after micelle dissociation and on resuspended pel- lets of CN micelles obtained by centrifugation. To further investigate the effect of ultrasound on $\mathrm{CN}$ micelles and also explore possible interactions between $\mathrm{CN}$ micelles and whey protein, $3 \mathrm{CN}$-containing milk powder systems were also examined: reconstituted micellar $\mathrm{CN}$ powder (MC) containing $\mathrm{CN}$ micelles and very little whey protein; reconstituted $\mathrm{CN}$ powder (NCN) containing nonmicellar $\mathrm{CN}$ and even smaller quantities of whey protein; and a high-protein powder with a $\mathrm{CN}$ :whey protein ratio of $1: 1$ by mass (CNWP). The knowledge gained from this study will enable a better understanding of observed functional changes to CNcontaining systems resulting from sonication.

\section{MATERIALS AND METHODS}

\section{Materials}

Fresh, pasteurized skim milk was purchased from a local supermarket and immediately stored at $4^{\circ} \mathrm{C}$; all analyses were performed within $2 \mathrm{~d}$. The composition of the milk was $33 \mathrm{~g} / \mathrm{L}$ of protein, $1.5 \mathrm{~g} / \mathrm{L}$ of fat, and $52 \mathrm{~g} / \mathrm{L}$ of lactose, as determined by the manufacturer. The MC and edible NCN powders were obtained from Murray Goulburn Nutritionals (Cobram, Victoria, Australia). Scanning electron microscopy images confirmed that the $\mathrm{CN}$ in the reconstituted $\mathrm{MC}$ powder was in a micellar form (data not shown). A high-protein CNWP powder was also supplied. The composition of the powders was determined by the manufacturer using standard methods (Table 1). Ultrapure water (MilliQ; Millipore, Billerica, MA) was used at all times.

\section{Reconstitution of the MC and NCN Powders}

The MC and NCN powders were reconstituted in MilliQ water to obtain 50 and $150 \mathrm{~g} / \mathrm{kg}$ solutions. To completely solubilize the powders, solutions were continuously stirred for $30 \mathrm{~min}$ at $50^{\circ} \mathrm{C}$ and a further $1 \mathrm{~h}$ at room temperature. The solutions were left overnight

Table 1. Composition of powders ${ }^{1}$

\begin{tabular}{lccc}
\hline Component & $\begin{array}{c}\text { MC } \\
(\%, \text { wt } / w t)\end{array}$ & $\begin{array}{c}\text { NCN } \\
(\%, w t / w t)\end{array}$ & $\begin{array}{c}\text { CNWP } \\
(\%, w t / w t)\end{array}$ \\
\hline Protein & 85.5 & 88.7 & 80.1 \\
CN & 80.0 & 88.7 & $\sim 40$ \\
Fat & 1.6 & 0.9 & 3.4 \\
Lactose & 0.6 & 0.1 & 3.1 \\
Ash & 7.3 & 1.7 & 6.9 \\
Moisture & 5.3 & 10.2 & 6.5 \\
\hline
\end{tabular}

${ }^{1} \mathrm{MC}=$ micellar $\mathrm{CN}$ powder containing $\mathrm{CN}$ micelles and very little whey protein; $\mathrm{NCN}=$ reconstituted $\mathrm{CN}$ powder containing nonmicellar CN and even smaller quantities of whey protein; $\mathrm{CNWP}=$ highprotein powder with a $\mathrm{CN}$ :whey protein ratio of $1: 1$ by mass. 
at $4^{\circ} \mathrm{C}$. The following day, solutions were equilibrated at $25^{\circ} \mathrm{C}$ for $1 \mathrm{~h}$ before sonication and analysis.

\section{Ultrasonication}

Milk was sonicated in $60-\mathrm{mL}$ aliquots in a glass vessel equipped with a cooling jacket, using a $20-\mathrm{kHz}, 450-$ W ultrasonic horn (19 mm in diameter, Sonifier 450; Branson, Danbury, CT) at amplitude of $50 \%$ for 1,5 , 10, 20, 30, or $60 \mathrm{~min}$. The actual power delivered to the solution was determined to be $31 \mathrm{~W}$ by calorimetry. During sonication, chilled water was circulated continuously to keep the temperature of the milk to within $10^{\circ} \mathrm{C}$ of room temperature.

\section{Particle Size Measurement}

Photon correlation spectroscopy (PCS) was used to determine particle size with a Malvern Autosizer 4700 PCS or a ZetaSizer instrument (Malvern Instruments Ltd., Malvern, Worcestershire, UK). Measurements were performed at $25^{\circ} \mathrm{C}$ at a scattering angle of $90^{\circ} \mathrm{C}$. Volume size distributions were determined using the CONTIN algorithm, and average particle size was determined of the basis of light-weighted intensity, using the method of cumulants. To determine the effects of sonication on the size of fat globules alone, particle size measurements were also conducted after dissociation of the CN micelles by diluting milk samples 10 -fold in 10 g/L of EDTA solution (EDTA powder; APS Finechem, Seven Hills, New South Wales, Australia; adjusted to pH 7 by addition of sodium hydroxide).

\section{Turbidity}

The turbidity of the milk samples was measured using a UV-visible spectrophotometer (Carey 3E; Varian, Palo Alto, CA) by transmission of light $(\lambda=860$ $\mathrm{nm})$ through a 2-mm path-length quartz cuvette. The turbidity of the samples diluted in EDTA solution was multiplied by 10 to account for the dilution.

\section{pH Measurement}

The $\mathrm{pH}$ of the milk was measured at $25^{\circ} \mathrm{C}$ by using a $\mathrm{pH}$ electrode with an integrated temperature sensor (Mettler Toledo Ltd., Port Melbourne, Victoria, Australia) connected to a Seven Easy $\mathrm{pH}$ meter (Mettler Toledo Ltd.). The $\mathrm{pH}$ probe was calibrated before each measurement at $25^{\circ} \mathrm{C}$ using standard buffers at $\mathrm{pH} 4.0$, 7.0, and 10.0 (Mettler Toledo Ltd.).

\section{Ultracentrifugation}

Milk samples were ultracentrifuged at $78,000 \times g$ at $25^{\circ} \mathrm{C}$ for 90 min by using a Beckman L8 80M ultracentrifuge with a type 50 rotor (Beckman Instruments Inc., Palo Alto, CA). All analyses were carried out on the clear supernatant.

\section{Resuspension of Pelleted Micellar Phase}

Pellets containing only $\mathrm{CN}$ micelles were obtained by centrifugation at $25,000 \times g$ for $60 \mathrm{~min}$ at room temperature by using a Beckman Avanti30 centrifuge with an F0685 rotor (Beckman Instruments Inc.). The firm pelleted phase was carefully removed to a beaker after several washes with water. The pellets were resuspended in simulated milk ultrafiltrate (i.e., $0.02 \mathrm{M}$ BisTris, $0.05 M$ sodium chloride, $0.003 M$ calcium chloride; $\mathrm{pH}$ 6.7) and stirred overnight. Before ultrasonication, the resuspended samples were centrifuged at $14,254 \times$ $g$ for $5 \mathrm{~min}$ at room temperature to remove any large, undissolved CN particles.

\section{Soluble Calcium Measurement}

Soluble calcium was determined by measuring the total calcium contained in supernatants of the ultracentrifuged milk samples. Residual protein was removed by diluting an aliquot $(5 \mathrm{~g})$ of supernatant sample with $20 \mathrm{~g}$ of MilliQ water and $25 \mathrm{~g}$ of $24 \mathrm{~g} / 100 \mathrm{~g}$ of TCA, followed by suction filtration through a Whatman no. 40 filter paper into a preweighed Büchner flask. The precipitated proteins were washed with $10 \mathrm{~g}$ of $12 \mathrm{~g} / 100 \mathrm{~g}$ TCA solution and the total mass of the TCA filtrate was recorded. An aliquot $(4.0 \mathrm{~g})$ of the supernatant was mixed with a suppressant $(2 \mathrm{~g}$ of lanthanum chloride) and diluted to a total mass of $10 \mathrm{~g}$. The calcium concentration was determined by atomic absorption spectroscopy (Varian Atomic Absorption Spectrophotometer, Mulgrave Victoria, Australia) using an air acetylene flame and wavelength of $422.7 \mathrm{~nm}$. Commercially available calcium standards for atomic absorption spectroscopy were used after appropriate dilution (0 to $6 \mathrm{mg} / \mathrm{mL}$ for calcium).

\section{Total Protein Measurement}

The total concentration of protein in the supernatants from ultracentrifugation was measured by Bradford assay according to the manufacturer's instructions (Sigma-Aldrich Pty. Ltd., Castle Hill, New South Wales, Australia). Whey protein concentration was estimated by measuring the total protein remaining after precipi- 
tation at $\mathrm{pH}$ 4.6. Casein concentration was calculated by subtracting the whey protein from the total protein.

\section{HPLC}

The supernatants of milk solutions obtained from ultracentrifugation were analyzed for $\mathrm{CN}$ concentration by reverse-phase HPLC after filtering through a 0.45$\mu \mathrm{m}$ syringe filter. Reverse-phase HPLC was performed using a Jupiter $5-\mu \mathrm{m} \mathrm{C18} \mathrm{300A} \mathrm{column}(250 \times 4.6 \mathrm{~mm}$ i.d.; Phenomenex, Torrance, CA). Analysis was performed with a solvent gradient using 2 solutions with different ratios of acetonitrile-water-trifluoroacetic acid (100:900:1 and 900:100:0.7, by vol) as reported previously (Visser et al., 1991).

\section{Viscosity Measurements}

The viscosity of the fresh skim milk and 5 wt\% powder solutions was measured using a type 531-03/0c capillary viscometer (SI Analytics GmbH, Mainz, Germany) maintained at $20^{\circ} \mathrm{C}$. The dynamic viscosity was determined by comparing the relative flow times and densities of the samples with those of distilled water. The viscosity of the $15 \mathrm{wt} \%$ powder solutions was determined using a Rheometrics ARG2 rheometer (TA Instruments c/o Waters Australia Pty Ltd., Rydalmere, New South Wales, Australia). A steady stress sweep experiment was carried out using $40-\mathrm{mm}$ parallel-plate geometry and a $1-\mathrm{mm}$ gap at $25^{\circ} \mathrm{C}$. The stress was varied to obtain the viscosity data between the shear rate of 50 to $200 \mathrm{~s}^{-1}$.

\section{RESULTS AND DISCUSSION}

\section{Investigation of the Stability of CN Micelles in Fresh Skim Milk}

Decreases in the average particle size and turbidity were observed over the $60 \mathrm{~min}$ of sonication of skim milk (Figure 1A and B). A decrease in particle size upon sonication of skim milk was also observed by others (Nguyen and Anema, 2010). This was attributed to a decrease in micelle size; however, the exact mechanism was not proposed.

Although the quantity of fat in skim milk is low in comparison with the $\mathrm{CN}$ content, the residual fat globules have a high relative refractive index and can be of considerable size. As such, they contribute significantly to the light-scattering properties of the milk, which influence both the turbidity and dynamic light-scattering signal. Because ultrasonication has been shown to be highly effective at reducing the size of fat globules in milk (Villamiel and de Jong, 2000; Wu et al., 2001), further investigation was required to determine whether the observed decreases in particle size and turbidity were due to alterations to the CN micelles, the fat globules, or whey or whey protein-CN aggregates formed during pasteurization. In this laboratory, it has often been observed that the fat globules in skim milk are similar in size to larger CN micelles $(\sim 200-300 \mathrm{~nm})$. Although asserting an influence on the average particle size (i.e., obtained from the method of cumulants) in the presence of $\mathrm{CN}$ micelles, they are not detectable as a separate peak in the volume size distribution (obtained using the CONTIN algorithm). To clearly observe the size distribution of the fat globules, it is necessary to first completely dissociate the $\mathrm{CN}$ micelles by addition of chelating agents that remove the colloidal calcium phosphate and disrupt the micelles (Udabage et al., 2000). Skim milk samples sonicated for different times were suspended in a solution of EDTA, dissociating the $\mathrm{CN}$ micelles. The particle size distribution of the fat globules was then examined by PCS and the turbidity of the samples was measured (Figure $1 \mathrm{C}$ and D).

A reduction in size of the fat globules as a function of sonication time was clearly evident in the particle size distribution of the EDTA-treated skim milk samples (Figure 1C). The peak at larger particle sizes corresponds to the fat globules, and the other peak corresponds to the products of the dissociated $\mathrm{CN}$ micelles. The average size of the peak corresponding to the fat globules decreased from approximately 230 to $175 \mathrm{~nm}$ after $60 \mathrm{~min}$ of sonication (Figure 1D). The turbidity of these samples also decreased as a function of sonication, declining from approximately 1.4 to $0.5 \mathrm{~cm}^{-1}$ after $60 \mathrm{~min}$ of sonication (Figure 1D). Further verification was provided by measuring the particle size and turbidity of sonicated skim milk samples immediately after sonication and again after $24 \mathrm{~h}$. The turbidity and size of all samples remaining unchanged after $24 \mathrm{~h}$, suggesting that the changes caused by sonication were not reversible. This is consistent with a breakdown of fat globules, which would be expected to remain stable after sonication. It is evident from these data and from similar results on other milk samples (data not shown) that a decrease in fat globule size causes a decrease in the average particle size and turbidity of fresh skim milk.

Although a decrease in fat globule size is responsible, at least in part, for the observed decrease in particle size, the possibility of a change in $\mathrm{CN}$ micelle size cannot be completely eliminated. To further investigate whether CN micelles are affected by sonication, CN micelles were isolated from the other milk components by centrifugation. Pellets obtained from centrifugation of fresh skim milk were resuspended and the particle 

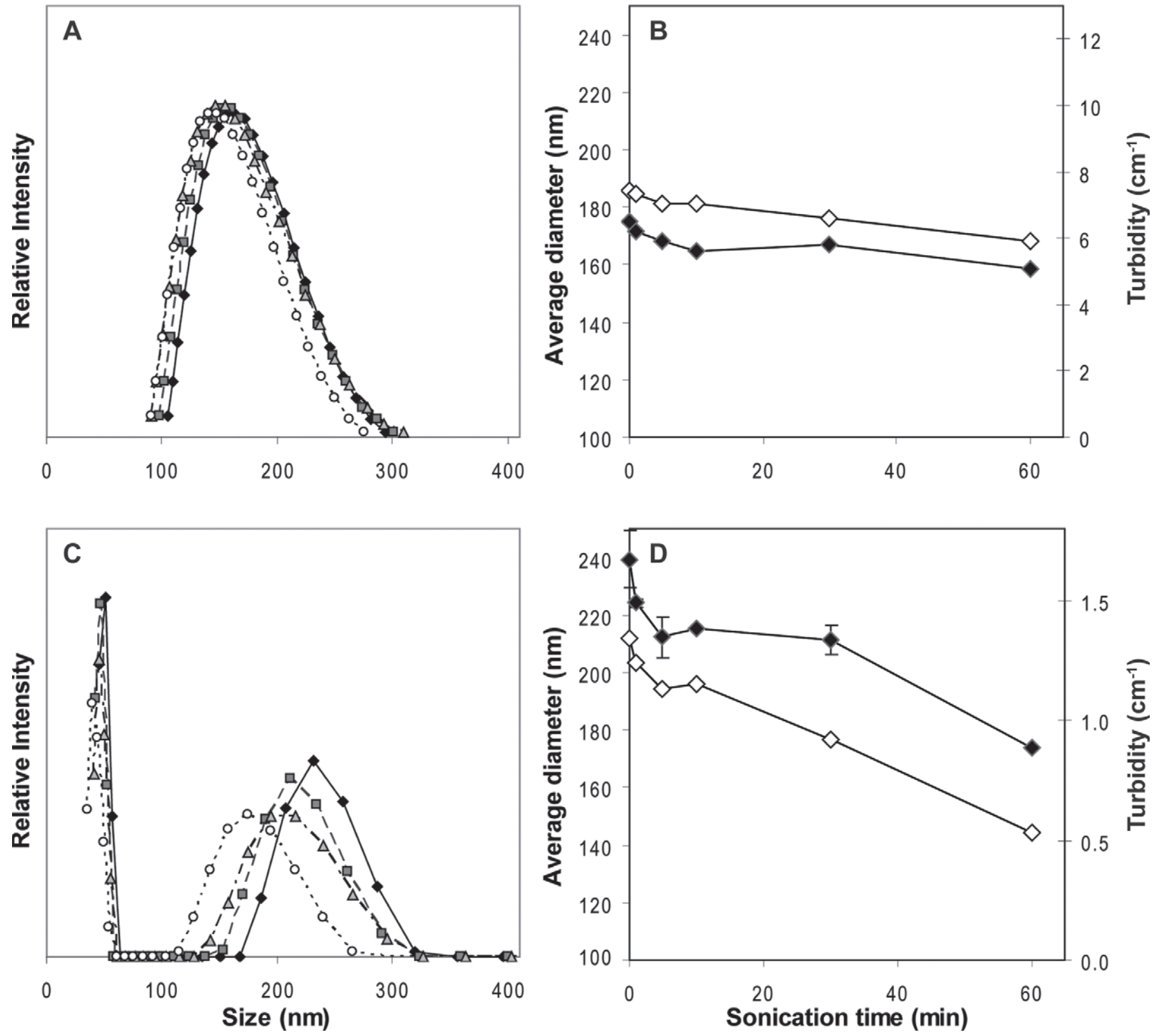

Figure 1. Intensity-weighted particle size distribution of fresh skim milk (A) and fresh skim milk with micelles dissociated by EDTA (C) as a function of sonication time: 0 min (solid diamonds and solid line); 1 min (shaded squares and long-dashed line); 30 min (shaded triangles and mixed-dashed line); 60 min (open circles and mixed-dashed line). Intensity-weighted average particle size (solid diamonds) and turbidity (open diamonds) of fresh skim milk (B) and fresh skim milk with micelles dissociated by EDTA (D) as a function of sonication time. Error bars are the standard deviation of triplicate measurements of the same sample.

size and turbidity were determined (data not shown). Both the turbidity and average particle size remained unchanged $\left(2.49 \pm 0.04 \mathrm{~cm}^{-1}\right.$ and $168 \pm 2 \mathrm{~nm}$, respectively) over $60 \mathrm{~min}$ of ultrasonication, providing strong evidence that the size of the $\mathrm{CN}$ micelles remained unaltered by exposure to ultrasound.

To further examine the structural stability of the $\mathrm{CN}$ micelles during sonication, the protein content of the serum phase was examined after sonication. The supernatants from ultracentrifugation were analyzed by HPLC and Bradford protein assays to determine whether sonication released any $\mathrm{CN}$ from the micelles or caused any interaction between whey protein and soluble CN. Consistent with previous observations (Nguyen and Anema, 2010), the results of the Bradford assay method and analysis of the individual free $\mathrm{CN}$ in 
the serum of fresh skim milk solutions by HPLC showed no significant change in concentrations of soluble $\mathrm{CN}$ as a result of ultrasonication (Figure $2 \mathrm{~A}$ and $2 \mathrm{~B}$ ). The amount of soluble whey protein was, however, observed to increase slightly in the first 1 to $5 \mathrm{~min}$ of sonication (Figure 2B). The observed increase in soluble whey protein could be due to the breakup of aggregated whey protein or whey protein associated with $\mathrm{CN}$ micelles (Ashokkumar et al., 2009b; Chandrapala et al., 2011) that may have formed during pasteurization of the fresh milk. Consistent with this explanation, the viscosity of fresh skim milk (with whey protein) was seen to decrease slightly from 1.71 to $1.65 \mathrm{cP}$ over the first minute of sonication and then remain stable (1.65 $\pm 0.02 \mathrm{cP})$, whereas the viscosity of resuspended pellets (without soluble whey protein) was seen to remain unchanged over $60 \mathrm{~min}$ of sonication $(1.15 \pm 0.02 \mathrm{cP})$. Although these results suggest ultrasonication may break up whey protein or CN-whey protein aggregates, again no changes to the $\mathrm{CN}$ micelles themselves could be seen to result from ultrasonication.

Minor changes to the $\mathrm{pH}$ were observed as a function of increased sonication time (Figure 2C). Ultrasound can alter the $\mathrm{pH}$ of a solution because of the formation of small amounts of nitric acid (Supeno and Kruus, 2000). The reaction between nitrogen and oxygen within the hot zone of the cavitation bubbles generates nitric acid. For raw skim milk samples, we found that the $\mathrm{pH}$ change was fully reversible within a few minutes (Figure $2 \mathrm{C}$ ), suggesting only a temporary disruption of the natural mineral equilibrium present in milk. The $\mathrm{pH}$ of milk is also sensitive to temperature; however, because the experiments in the present study were performed under temperature-controlled conditions (within $10^{\circ} \mathrm{C}$ ), the observed $\mathrm{pH}$ decrease was more likely due primarily to nitric acid formation. Even slight changes in $\mathrm{pH}$ may affect the mineral equilibria of milk, which in turn could affect the composition of CN micelles. However, no measurable differences in the soluble calcium could be observed as a result of the temporary $\mathrm{pH}$ decrease caused by sonication (Figure $2 \mathrm{C}$ ).

\section{CN-Containing Powders}

To further investigate the effect of ultrasonication on $\mathrm{CN}, 3$ different powder systems were examined: MC, NCN, and CNWP. The turbidity and average particle size of reconstituted MC were observed to decrease rapidly in the first $10 \mathrm{~min}$ and then stabilize (Figure $3 \mathrm{~A})$. The initial decrease could presumably be due to a breakup of micelle aggregates remaining from powder solubilization, a breakup in whey protein or whey protein-CN aggregates, or simply a decrease in the size of any fat globules present. A corresponding initial de-
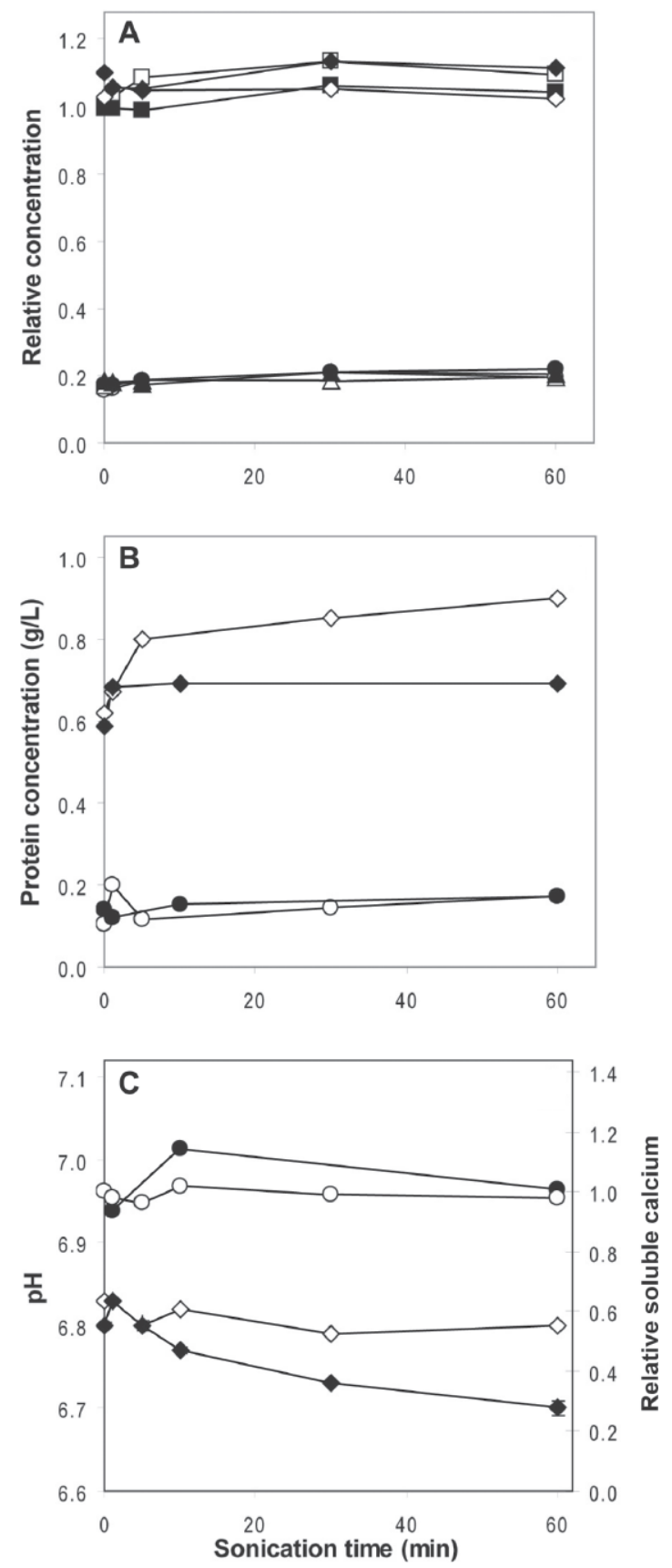

Figure 2. Relative concentration of soluble CN of skim milk ultrasonicated for different times (A). Results are HPLC peak intensities of $\kappa-\mathrm{CN}$ (open and solid circles), $\alpha_{\mathrm{S}_{1}} \mathrm{CN}$ (open and solid diamonds), $\alpha_{S_{2}-} \mathrm{CN}$ (open and solid triangles), and $\beta$-CN (open and solid squares) in supernatants of ultracentrifuged samples normalized to that of $\beta-\mathrm{CN}$ in the unsonicated sample. Open and closed symbols represent samples ultracentrifuged immediately or $24 \mathrm{~h}$ after sonication, respectively. Estimated concentrations of $\mathrm{CN}$ (open and solid circles) and whey protein (open and solid diamonds) in the serum of fresh skim milk samples as determined by Bradford assays of total soluble protein and soluble protein remaining after $\mathrm{CN}$ precipitation at $\mathrm{pH} 4.6$ (B). Data shown are the results of measurements of 2 different skim milk samples. The $\mathrm{pH}$ (open and solid diamonds) and soluble calcium concentration (open and solid circles) of fresh skim milk samples as a function of sonication time (C). Closed and open symbols represent measurements taken immediately or $24 \mathrm{~h}$ after sonication, respectively. 
crease in turbidity was also observed (Figure 3B). As with fresh skim milk, a small and reversible decrease in $\mathrm{pH}$ was seen to result from sonication (Figure 3C). In this case, a slight and reversible increase in the soluble calcium could also be seen after 60 min of sonication (Figure 3C). According to the Bradford assays, ultrasonication had no measurable influence on either the whey protein or soluble $\mathrm{CN}$ concentration (Figure $3 \mathrm{D}$ ).
These results are again consistent with the suggestion that ultrasonication had no effect on the CN micelles. A large reduction in both the average particle size and turbidity of reconstituted NCN powder was seen after only $10 \mathrm{~min}$ of sonication (Figure 4A). The extremely low turbidity is consistent with the CN being present in nonmicellar form. The particles observed by PCS were initially larger than CN micelles $(280 \mathrm{~nm})$ and most
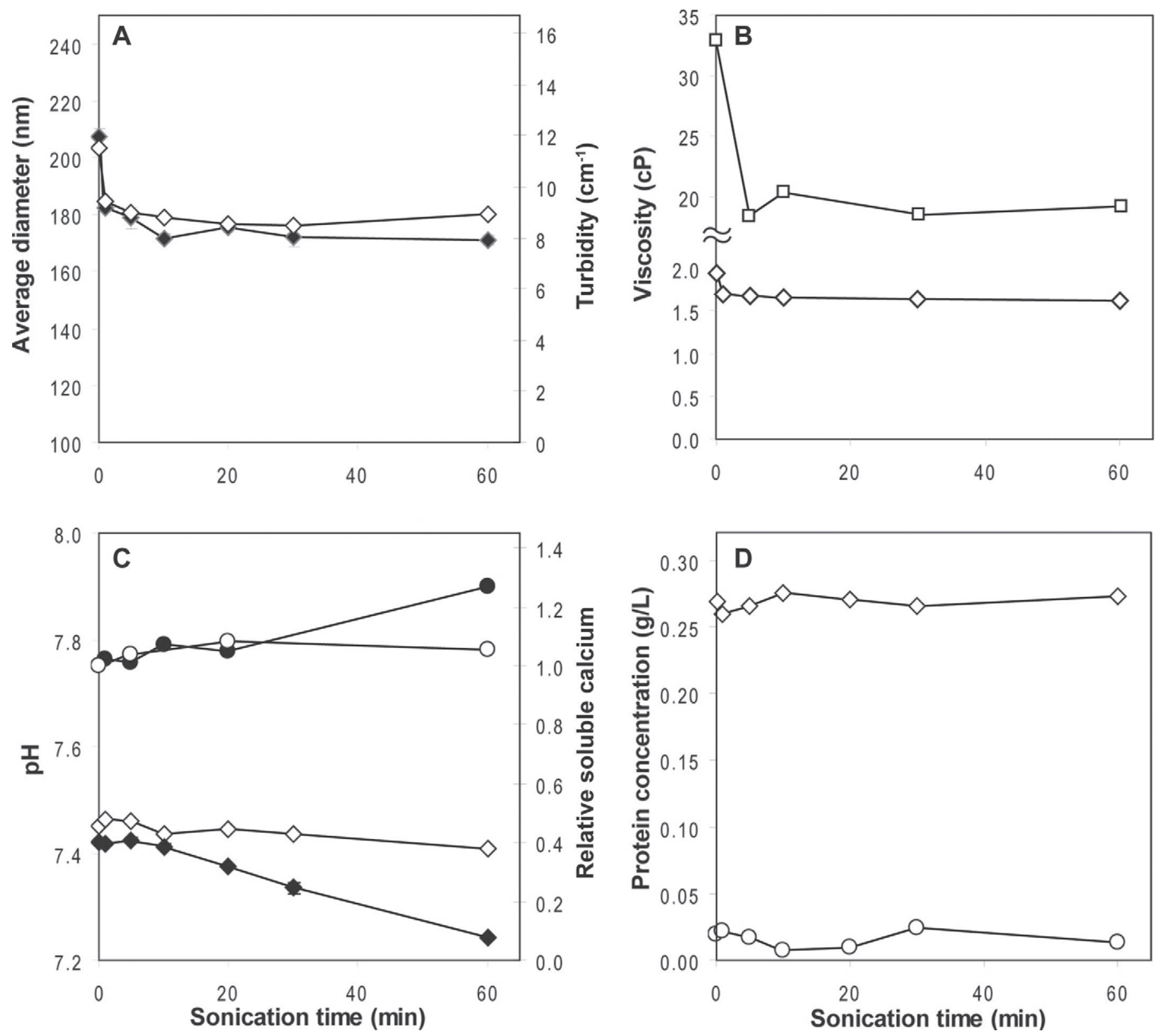

Figure 3. Intensity-weighted average particle size (solid diamonds) and turbidity (open diamonds) of $5 \%$ micellar CN as a function of sonication time (A). Viscosity of $5 \%$ (open diamonds) and $15 \%$ (open squares) micellar CN as a function of sonication time (B). pH (open and solid diamonds) and soluble calcium concentration (open and solid circles) of $5 \%$ micellar CN as a function of sonication time (C). Closed and open symbols represent measurements taken immediately or $2 \mathrm{~h}$ after sonication, respectively. Estimated concentration of CN (open circles) and whey protein (open diamonds) in the serum of fresh skim milk samples as determined by Bradford assays of total soluble protein and soluble protein remaining after $\mathrm{CN}$ precipitation at $\mathrm{pH} 4.6(\mathrm{D})$. 

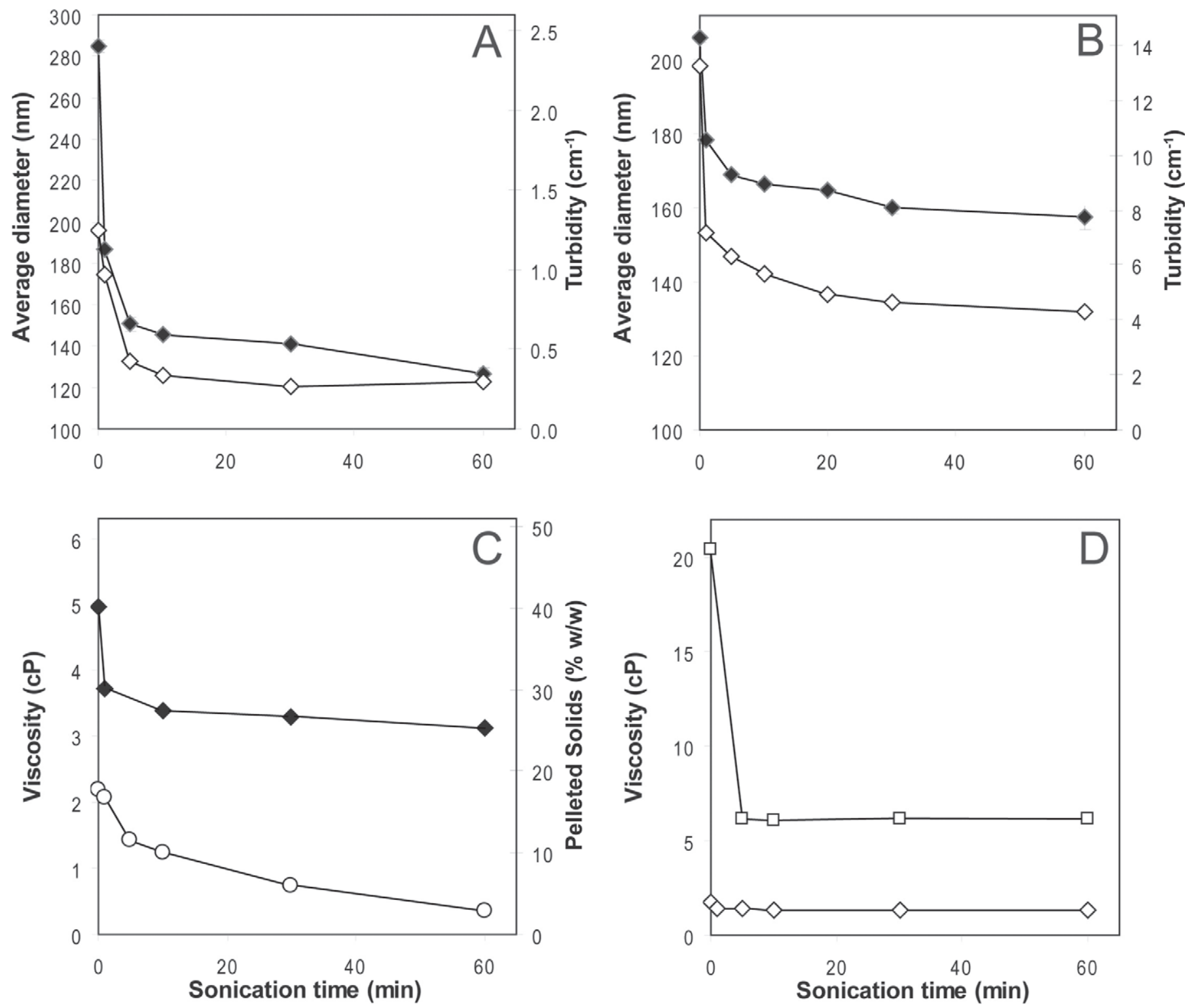

Figure 4. Intensity-weighted average particle size (solid diamonds) and turbidity (open diamonds) of a $5 \%$ nonmicellar CN powder (A) and a $5 \%$ high-protein powder with a CN:whey protein ratio of 1:1 (CNWP; B) as a function of sonication time. The viscosity (solid diamonds) and mass of pelleted solids (open circles) of $5 \%$ nonmicellar CN as a function of sonication time (C). The viscosity of $5 \%$ (open diamonds) and $15 \%$ (open squares) CNWP powder as a function of sonication time (D).

likely to be small fat globules (the powder contained $0.9 \%$ fat) or protein aggregates that were rapidly broken down by sonication. The size and turbidity continued to decrease, although to a much lesser extent over the 60 -min period tested. The viscosity and amount of solid material pelleted by centrifugation were also observed to decrease as a function of sonication time (Figure $4 \mathrm{C})$. These results in particular are consistent with sonication breaking up nonmicellar protein aggregates that remained after powder solubilization at $50^{\circ} \mathrm{C}$ and overnight equilibration.
It has previously been shown that ultrasonication can break aggregates of whey protein without causing denaturation of individual protein molecules (Ashokkumar et al., 2009b; Chandrapala et al., 2011). The results presented in this paper suggest analogous behavior with $\mathrm{CN}$; $\mathrm{CN}$ aggregates held together by denatured whey proteins are disrupted without affecting the native state of the CN micelles. Further experiments were performed on the high-protein CNWP powder. Application of ultrasound decreased the viscosity by approximately $20 \%$ after 5 min and then had little fur- 
ther effect (Figure 4D). The particle size was reduced from 205 to $165 \mathrm{~nm}$ within $10 \mathrm{~min}$ of sonication and to $160 \mathrm{~nm}$ after $60 \mathrm{~min}$, and the turbidity decreased concomitantly (Figure 4B). More concentrated (15\% wt/ wt) solutions for both of the CNWP and MC systems showed similar trends, although the relative viscosity reduction was much greater for the CNWP that contained whey protein (cf. Figures 3B and 4D). For both systems, a much greater viscosity reduction was observed than with $5 \% \mathrm{wt} / \mathrm{wt}$ solutions. These results are again consistent with ultrasonication disrupting whey protein, whey protein-CN micelle aggregates, or both over a short period without appearing to modify the native whey protein or $\mathrm{CN}$ structure on prolonged exposure.

\section{CONCLUSIONS}

Ultrasonication did not appear to affect $\mathrm{CN}$ micelle size or composition or to permanently affect the mineral balance in fresh skim milk. Ultrasonication did, however, reduce the size of the already small fat globules remaining in skim milk, did appear to break up whey protein aggregates, and did assist in breaking apart CN micelle, nonmicellar $\mathrm{CN}$, and whey protein aggregates present in reconstituted $\mathrm{CN}$ powder systems. Controlled application of ultrasonic energy can help break up large $\mathrm{CN}$ and whey protein aggregates, thereby influencing macroscopic properties, such as viscosity, without inducing changes to the $\mathrm{CN}$ micelles or mineral balance. Ultrasonication can be used as a processing tool in CN-containing milk systems with minimal damage to key milk components. In particular, it appears that ultrasound can help reverse protein aggregation caused by prior processing without affecting the native state of the milk proteins or mineral equilibrium. This is an important observation for a range of industry applications.

\section{ACKNOWLEDGMENTS}

The present study was supported by Australian Research Council (Majura Park, Australian Capital Territory, Australia) and Dairy Innovation Australia Pty Ltd. (Werribee, Victoria, Australia).

\section{REFERENCES}

Ashokkumar, M., S. E. Kentish, J. Lee, B. Zisu, M. Palmer, and M. A. Augustin, inventors. 2009a. Processing of dairy ingredients by ultra-sonication. Dairy Innovation Australia Pty. Ltd., assignee. PCT Int. Appl. WO2009/079691.
Ashokkumar, M., J. Lee, S. E. Kentish, and F. Grieser. 2007. Bubbles in an acoustic field: An overview. Ultrason. Sonochem. 14:470475 .

Ashokkumar, M., J. Lee, B. Zisu, R. Bhaskaracharya, M. Palmer, and S. E. Kentish. 2009b. Hot topic: Sonication increases the heat stability of whey proteins. J. Dairy Sci. 92:5353-5356.

Ashokkumar, M., D. Sunartio, S. E. Kentish, R. Mawson, L. Simons, K. Vilkhu, and C. Versteeg. 2008. Modification of food ingredients by ultrasonication to improve functionality: A preliminary study on a model system. Innov. Food Sci. Emerg. Technol. 9:155-160.

Chandrapala, J., B. Zisu, M. Palmer, S. E. Kentish, and M. Ashokkumar. 2011. Effects of ultrasound on the thermal and structural characteristics of proteins in reconstituted whey protein concentrate. Ultrason. Sonochem. 18:951-957.

Dalgleish, D. G. 2011. On the structural models of bovine casein micelles-Review and possible improvements. Soft Matter 7:22652272

Madadlou, A., M. E. Mousavi, Z. Emam-Djomeh, M. Ehsani, and D. Sheehan. 2009. Sonodisruption of re-assembled casein micelles at different $\mathrm{pH}$ values. Ultrason. Sonochem. 16:644-648.

Martin, G. J. O., R. P. W. Williams, and D. E. Dunstan. 2007. Comparison of casein micelles in raw and reconstituted skim milk. J. Dairy Sci. 90:4543-4551.

Mounsey, J. S., B. T. O'Kennedy, and P. M. Kelly. 2005. Comparison of re-micellised casein prepared from acid casein with micellar casein prepared by membrane filtration. Lait 85:419-430.

Nguyen, N. H. A., and S. G. Anema. 2010. Effect of ultrasonication on the properties of skim milk used in the formation of acid gels. Innov. Food Sci. Emerg. Technol. 11:616-622.

Piyasena, P., E. Mohareb, and R. C. McKellar. 2003. Inactivation of microbes using ultrasound: A review. Int. J. Food Microbiol. $87: 207-216$

Riener, J., F. Noci, D. A. Cronin, D. J. Morgan, and G. Lyng. 2009. The effect of thermosonication of milk on selected physicochemical and microstructural properties of yoghurt gels during fermentation. Food Chem. 114:905-911.

Riener, J., F. Noci, D. A. Cronin, D. J. Morgan, and G. Lyng. 2010. A comparison of selected quality characteristics of yoghurts prepared from thermosonicated and conventionally heated milks. Food Chem. 119:1108-1110.

Supeno, and P. Kruus. 2000. Sonochemical formation of nitrate and nitrite in water. Ultrason. Sonochem. 7:109-113.

Tsioulpas, A., M. J. Lewis, and A. S. Grandison. 2007. Effect of minerals on casein micelle stability of cows' milk. J. Dairy Res. 74:167-173.

Udabage, P., I. R. McKinnon, and M. A. Augustin. 2000. Mineral and casein equilibria in milk: Effects of added salts and calciumchelating agents. J. Dairy Res. 67:361-370.

Vercet, A., R. Oria, P. Marquina, S. Crelier, and P. Lopez-Buesa 2002. Rheological properties of yoghurt made with milk submitted to manothermosonication. J. Agric. Food Chem. 50:6165-6171.

Villamiel, M., and P. de Jong. 2000. Influence of high intensity US and heat treatment in continuous flow in fat, proteins and native enzymes of milk. J. Agric. Food Chem. 48:472-478.

Visser, S., C. J. Slangen, and H. S. Rollema. 1991. Phenotyping of bovine milk proteins by reverse phase high performance liquid chromatography. J. Chromatogr. A 548:361-370.

Wu, H., G. J. Hulbert, and J. R. Mount. 2001. Effects of ultrasound on milk homogenization and fermentation with yogurt starter. Innov. Food Sci. Emerg. Technol. 1:211-218.

Zisu, B., R. Bhaskaracharya, S. Kentish, and M. Ashokkumar. 2010. Ultrasonic processing of dairy systems in large scale reactors. Ultrason. Sonochem. 17:1075-1081.

Zisu, B., J. Lee, J. Chandrapala, R. Bhaskaracharya, M. Palmer, S. E. Kentish, and M. Ashokkumar. 2011. Effect of ultrasound on the physical and functional properties of reconstituted whey protein powders. J. Dairy Res. 78:226-232 